
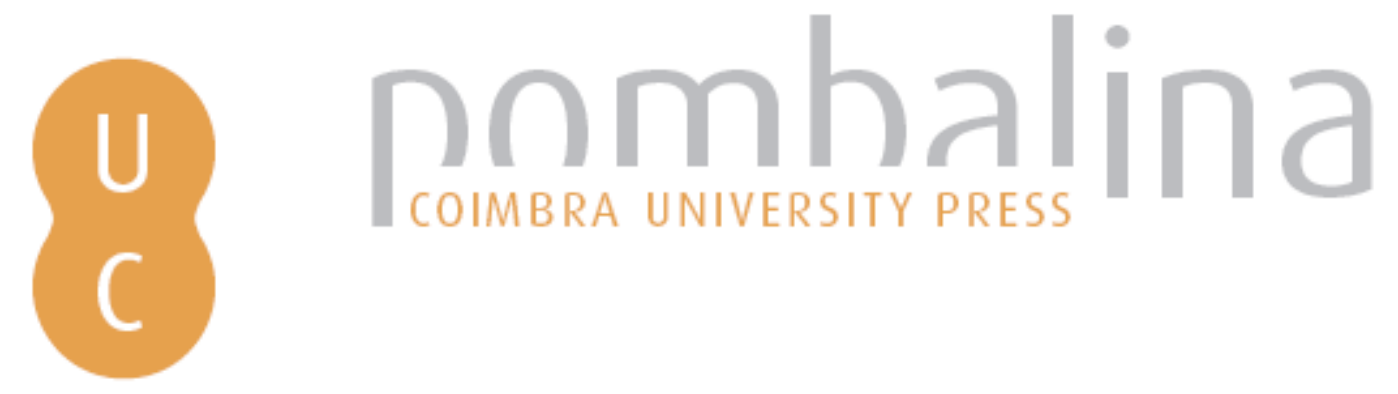

As tradições do pão, territórios e desenvolvimento

Autor(es): $\quad$ Santos, Norberto Pinto dos; Gama, António

Publicado por: Imprensa da Universidade de Coimbra

URL

persistente: URI:http://hdl.handle.net/10316.2/30794

DOI: $\quad$ DOI:http://dx.doi.org/10.14195/978-989-26-0244-8_29

Accessed : $\quad$ 26-Apr-2023 00:53:25

A navegação consulta e descarregamento dos títulos inseridos nas Bibliotecas Digitais UC Digitalis, UC Pombalina e UC Impactum, pressupõem a aceitação plena e sem reservas dos Termos e Condições de Uso destas Bibliotecas Digitais, disponíveis em https://digitalis.uc.pt/pt-pt/termos.

Conforme exposto nos referidos Termos e Condições de Uso, o descarregamento de títulos de acesso restrito requer uma licença válida de autorização devendo o utilizador aceder ao(s) documento(s) a partir de um endereço de IP da instituição detentora da supramencionada licença.

Ao utilizador é apenas permitido o descarregamento para uso pessoal, pelo que o emprego do(s) título(s) descarregado(s) para outro fim, designadamente comercial, carece de autorização do respetivo autor ou editor da obra.

Na medida em que todas as obras da UC Digitalis se encontram protegidas pelo Código do Direito de Autor e Direitos Conexos e demais legislação aplicável, toda a cópia, parcial ou total, deste documento, nos casos em que é legalmente admitida, deverá conter ou fazer-se acompanhar por este aviso. 


\section{TRUNFOS DE UMA}

\section{EOGRAFIA ACIVA}

\section{DESENVOLVIMENTO LOCAL,}

AMBIENTE,

ORDENAMENTO

E TECNOLOGIA

Norberto Santos

Lúcio Cunha

COORDENAÇÃO 


\author{
Norberto Pinto dos Santos ${ }^{1}$, António Gama ${ }^{2}$ \\ ${ }^{1}$ CEGOT \\ ${ }^{2} C E S$
}

\title{
AS TRADIÇÓES DO PÃO, TERRITÓRIOS E DESENVOLVIMENTO
}

\section{INTRODUÇÃO. DA DESCOBERTA DO TERRITÓRIO À REINVENÇÃO DO LUGAR.}

A alimentação é um dos meios privilegiados para as sociedades efectuarem trocas de valores, relaçóes identitárias e prazeres.

A relação com a alimentaçáo pode considerar-se análoga com a linguagem: ambas parecem "naturais", obedecem a regras indiscutíveis e inconscientes que são apreendidas desde a infância, no ambiente familiar; tal como a linguagem, a alimentação pode modifi-car-se com a alteração do ambiente e reflectir determinadas situaçóes sociais, económicas e religiosas (Valeri, 1989).

A alimentação expressa ainda uma diferenciação de civilizaçóes porque é pela comensalidade que surge a distinção entre o homem civilizado e os bárbaros: o primeiro junta ao alimento do corpo a valorização do espírito através da sociabilidade, algo que os segundos não fazem.

Entre os alimentos, o pão tem um papel central, sendo também ele diferenciador de classes e status. Em cada sociedade, a hierarquia dos valores alimentares corresponde, pelo menos em parte, à hierarquia dos grupos sociais. (Valeri, 1989). Contudo o pão foi sempre um alimento que atravessou as diferenças. Foi sempre a base de toda a ordem alimentar para ricos e pobres, tanto em meio rural como urbano, se bem que em algumas épocas, assuma uma centralidade maior devido à dificuldade em aceder a outro tipo de alimentos.

Mas o pão, se revela áreas civilizacionais, diz-nos também muito sobre a terra, o clima e o saber/fazer das populaçóes. Produto de civilização através do domínio da arte do fogo, cobre uma variedade de tipos ao sabor do cereal de que é feito, mas também das terras e das gentes que o fazem. É como produto da terra e das suas gentes que o queremos mostrar neste texto.

\section{TERritório E LUGAR. OS PRODUTOS DA TERRA.}

Território e lugar designam espaços sociais de sentidos diferentes: diferença e convergência. Território e lugar aparecem muitas vezes associados, mesmo indiferenciados. Consideramos o território como um espaço socializado em que se expressa uma apropriaçáo e, mesmo, uma dominação.

O território é, pois, um espaço (social) dominado, apropriado, que se manifesta a diversas escalas, que vão desde as da vida quotidiana até ao espaço mundo, passando necessariamente pelo Estado. 
Por sua vez entendemos lugar como um espaço dotado de sentido; de relação afectiva. $\mathrm{O}$ espaço transforma-se em lugar à medida que adquire significação como expressão de identidade.

Tuan (1970) dá ao lugar a dimensão estética, associada à visão, mas também à audição, ao olfacto, ao tacto e ao paladar, que diferentemente da visão, requerem proximidade e associaçóes duradouras com o ambiente.

Tuan (1970) acrescenta-lhe, ainda, as dimensôes de intimidade, onde encontramos o carinho e a atençáo, e de permanência, porque as coisas e os objectos são resistentes ao tempo, funcionando como âncoras que a memória consolida (Connerton, 1993). Cada um de nós participa na criação de lugares, dos nossos lugares (Cresswell, 2004). Eles são transformados a partir de espaços que nada ou pouco nos diziam, mas que devido ao facto de passarmos a ter com eles uma cumplicidade, uma partilha, tornamo-los nossos. Efectivamente passam a ser palcos de acçóes de apropriação, de necessidades, de interesses e de desejos.

A perspectiva da relaçáo entre produto (no nosso caso o pão) e lugar, que aqui vamos sublinhar, pode ser convertida em fomentadora do desenvolvimento local e da imagem dos lugares, transformando-se em factores da sua patrimonialização.

A ideia de lugar envolvendo "relaçôes sociais alargadas" e o "alcance espacial das relaçôes sociais” (MASSEY, 1994) é atraente num mundo contemporâneo fustigado por forças globalizadoras; os lugares tornam-se dinâmicos, contestados e múltiplos nas suas qualidades simbólicas e de representantes de posiçóes identitárias. (Cartier \& Lew, 2005)

A importância do território e dos lugares gera, de modo incontornável, a interpretação das suas relaçóes concorrenciais com outros espaços que identitariamente se assemelham ou diferenciam. Devido à grande diversidade, às dualidades e às ambiguidades, como refere Dollfus (2001) simultaneamente espaciais e sociais, a concorrência perfeita entre os lugares não existe, sendo que as diferenças são assumidas através das potencialidades dos lugares. Estes recursos dos lugares são o resultado de percepçóes e representaçóes diversas, que para DiMéo (1998) envolvem abordagens que se complementam: a descritiva, espacial e social; a política, de controlo e ordenamento; a simbólica, de identidade colectiva e pertença.

É referência central neste texto o entendimento dos lugares como um valor recurso, integrando bens, produtos e imagens com que se relacionam e resultantes do saber/fazer das populaçóes que usam o seu espaço como espaço de vida.

Assim, para Gama (1992), o espaço é produto e produtor, quer material quer simbólico, seguindo de perto a ideia de Lefèbvre (1974) que via o espaço como lugar de práticas de relação e veículo de representação. O lugar é, para cada um de nós, uma condição de experiência humana. Enquanto agentes estamos sempre no lugar, tal como estamos sempre na cultura. Por isso, as nossas relaçóes com o lugar e a cultura tornaram-se elementos da nossa identidade individual e colectiva (Entrinkin, 1991).

\subsection{Sentidos plurais do terroir. O lugar, a cultura e o pão}

São as relações com a cultura que nos enquadram quando se procura fazer a ligação entre lugar e terroir. Este é entendido como território agrícola trabalhado e resultante de influências várias: da morfologia que serve de suporte; das características dinâmicas do mundo físico, que condiciona as acçóes; das relaçóes que se estabelecem com o saber/fazer dos seus habitantes; da imagem transmitida a partir dele. O terroir, muito apoiado no 
valor cultural resultante das relaçôes entre o económico, o político e o simbólico, ganha, pois, uma dinâmica própria função da escala de acção, a local. Este, por sua vez, vinca uma relação forte e tendencialmente irrepetível entre o produto e o lugar em que é produzido, característica a que pretendemos dar maior expressividade.

Assim, um produto de terroir é aquele, como nos diz Brunet et al. (1993), que não poderia ser produzido noutro lugar que não naquele terroir. Portanto, o terroir, na relaçáo que aqui se pretende efectuar entre pão e tradição, será o resultado de uma combinação entre meio local de produção e saber/fazer, que contribuiriam, por usa vez, para a natureza e para a qualidade específica de um produto e em particular de um alimento (Levy et al., 2003).

A relação lugar/produto ganha tamanha importância que os legisladores se vêem na obrigação de a definir. A certificação surge, então, como definidora da qualidade do produto, do carácter inclusivo dos lugares, de marcas, raças ou variedades, de condiçóes naturais necessariamente presentes, de processos de elaboração e de utensílios requeridos.

Ascher (2009) conta-nos a história do pimento de Espelette (País Basco), desconhecido fora da sua região, há alguns anos atrás, mas, hoje presente em quase todas as boas mesas. Todavia, a presença náo é apenas de um produto mas de toda uma população em torno de um produto do seu solo; para o qual criou uma confraria e inventou uma festa.

E qual foi o ponto de partida desta afirmaçáo gastronómica de um produto/lugar basco? $\mathrm{O}$ instrumento que permitiu esta mais-valia foi precisamente a Denominação de Origem Controlada (DOC). "A DOC garante não só a origem geográfica e genética de um produto, mas também uma maneira de cultivar ou de o preparar" (Ascher, 2009). Faz-se aqui a apologia de o produto depender da sua origem geográfica, quer dizer, do solo e dos homens que o produzem.

Por outro lado, importa salientar que é criado um pacote de informação que surge associado ao produto que transporta consigo o gérmen de uma identidade local o qual promove, com acrescida frequência, a vontade do consumo in loco, perante o consumo noutros espaços fora do seu lugar de produção - especialmente num mundo em contínua compressão espacial Harvey (1989). Consumir o produto é também conhecer os lugares, onde foi criado, e as pessoas responsáveis pela sua produção, o saber/fazer, a cultura que está por detrás do produto gastronómico. Esta identidade lugar/produto está na base das DOC que, na verdade, patrimonializam os terroirs ao estabelecer normas e especificidades, dando azo a que a origem geográfica se torne, em simultâneo, origem histórica. Importa assumir que "as regiôes e os terroirs não são factos da natureza, mas construçôes" (Ascher, 2009).

\subsection{Os produtos da terra e a alimentação: Gastronomia e pão}

A alimentação, como no início referimos, é um dos actos de socialização privilegiados para as pessoas efectuarem trocas de valores, relaçóes identitárias e prazeres. Montanari \& Pitte (2009), afirmam mesmo que logo que descobrem as riquezas gastronómicas dos seus vizinhos, as pessoas não fazem a guerra e as fronteiras divertem-nos mais do que os irritam ou promovem instintos belicosos. Assume-se, então, que as fronteiras alimentares, funcionam como meio de patrimonialização dos produtos nos lugares, são, todavia, muito mais porosas e fluidas. De facto, a história e a geografia alimentares estão cheias de alimentos e bebidas migrantes, por vezes sós, por vezes nas bagagens materiais e culturais das pessoas migrantes. É o caso do bacalhau e dos portugueses. 
Esta perspectiva, desenvolvida em torno da alimentação em geral, é igualmente importante para o pão. Alimento de suporte de grande parte das dietas alimentares de diferentes civilizaçóes, o pão tem uma história muito antiga sendo possível encontrar referências desde o neolítico. Além disso, o pão simboliza tanto o alimento essencial da humanidade como o elemento de comunicaçáo com o divino, função sagrada que expressa a sua importância no quotidiano das pessoas. Não é por acaso que na religião cristã constitui o corpo de Cristo (Belém significa casa de pão e nela nasceu Jesus). Mas o seu papel simbólico leva-o mesmo a assumir significados relevantes para além da religiáo e é referido como o principal argumento da recompensa pelo trabalho realizado, como podemos perceber na expressão ganharás o pão com o suor do teu rosto, quando no livro do Génesis se menciona a necessidade de trabalhar para viver. Por sua vez, no âmbito económico, o grão constituiu, durante séculos, o verdadeiro valor monetário nas operaçóes económicas. Tributos, rendas, foros, etc., exprimiam-se quase sempre em alqueires, moios, carros de pão, ou pães cozidos e só muito raramente em dinheiro (Fonseca, 1986). Falar de pão é outra forma de interpretar a História. Cada país tem a sua história, cada terra tem o seu páo (Fernandez, 2009).

Saber valorizar este recurso, em associação com as estórias do lugar e com o saber/fazer dos autóctones, permite-nos mostrar que a tradição já não é o que era, mas é algo que pode ser usado para o desenvolvimento dos lugares, para patrimonializar produtos/lugares e integrá-los em itinerários de visita e de turismo.

\subsection{A cultura dos cereais e as terras do pão.}

A cultura do cereal está profundamente ligado às heranças civilizacionais, não sem que, contudo, devamos considerar o clima e os solos porque de plantas se trata por mais artifícios que a nossa civilização técnica tenha engendrado. Se à escala mundial podemos fazer corresponder os cereais a civilizaçóes numa visão de uma história de longa duração, a modernidade e sobretudo a última globalização foram diluindo as diferenciaçóes originais.

As geografias da primeira metade do século passado fundavam, à escala global, as geografias da alimentação na zonalidade.

A uma outra escala, quando nos debruçamos sobre o território de Portugal Continental, numa época em que a ruralidade imperava, pode fazer-se a correspondência entre a cultura do cereal e os tipos de pão. Para Girão (1958), o regime alimentar dos portugueses apresentava vincado carácter mediterrânico, só o extremo noroeste se aproxima um pouco do tipo europeu setentrional, e o pão - de trigo, de milho e de centeio - constituía a base da alimentação em todo o País. O pão variava segundo a região segundo o clima e a constituição dos solos, criando diferenciaçôes em cujas franjas aparecem situaçóes de hibridismo.

Todavia era nas planuras alentejanas que ele aparecia como marca indelével do modo de vida das populaçóes autóctones, (Figura 1), nas Imagens Regionais, desenhadas por Helena Abreu para o Atlas de Amorim Girão, em 1956.

A produção cerealífera portuguesa está directamente relacionada com as formas de exploração agrícola, com as temperaturas e com a pluviometria. O pão em Portugal é feito com três cereais: o milho, o centeio e o trigo. No seu Atlas de Portugal, Girão (1958) 
informa-nos que o milho se adapta melhor a terras pluviosas, mas está também presente, se bem com produções mais reduzidas, para sul ao longo da costa e no Algarve (Figura 2). Por seu lado, o centeio surge associado a terras mais acidentadas e frias, do Nordeste ao Tejo e mesmo para sul deste, no distrito de Portalegre (Figura 2). Quanto ao trigo (Figura 2), ele "cobre toda a metade meridional do País e avança muito para o norte ao longo da fronteira terrestre. É o cereal das regióes mais quentes e mais secas” (Girão, 22, 1958).

Figura 1 - As regióes portuguesas.

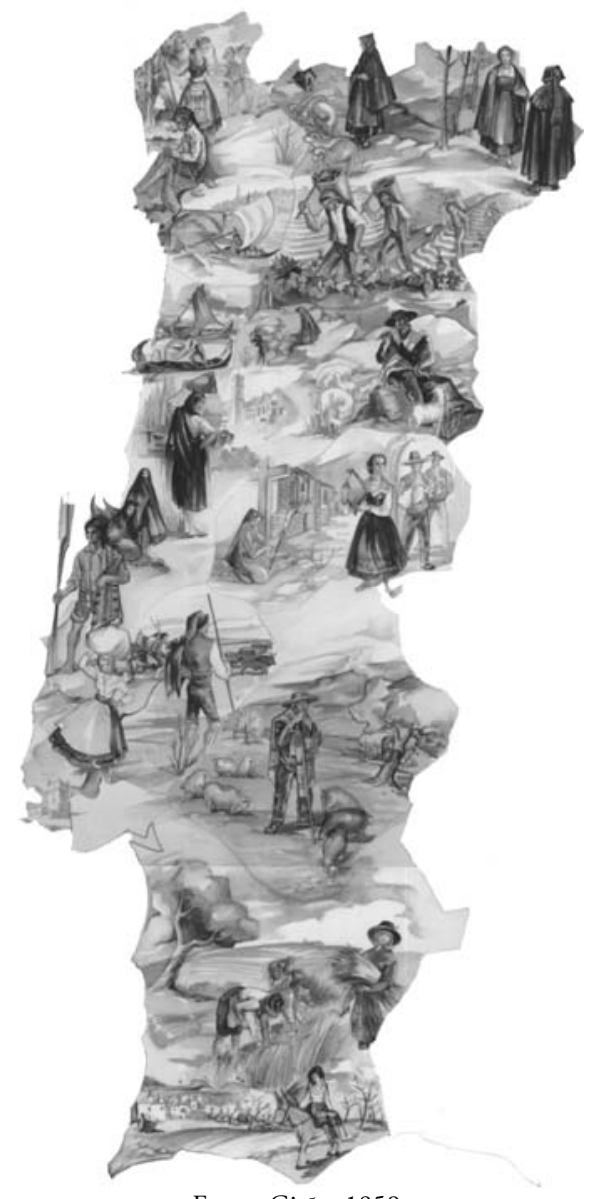

Fonte: Girão, 1958.

O etnólogo Leite de Vasconcelos evocava, em 1920, “curiosas formas de pães, cada um com um nome especial: cacete (pãozinho de trigo estreito, com uns 30 centímetros de comprimento), molete, pão podre (por oposição ao pão de trigo), sêmea ou pão segundo (em oposição ao pão alvo), trigamilha (pão de farinha de milho com uma percentagem de trigo), cancra, pão minheiro e pão Rolão (por oposição ao pão branco ou pão fino), papo-seco (pão pequeno com cerca de $10 \mathrm{com}$ de comprimento), pão de quartos e, excepcionalmente, pão de cevada e pão de aveia" (Barboff, 2008). 
Ao pão estão associadas outras formas de alimentação. Girão fala-nos do Caldo (Figura 2) a Norte do Tejo, normalmente casado com pão partido à força de mão; das Migas e da Açorda a sul do Tejo, em que o pão sofre outras cozeduras e transformaçóes; até ao Xérem algarvio que usa a farinha de milho para agregar alguns produtos de origem animal (carne e bivalves) e que era confeccionado com gráos de milho seco quebrados no pilâo, cozidos em água e sal. A estas sopas há que juntar as de Cavalo Cansado, que muitas vezes serviram de mata-bicho e para enganar a fome a uma populaçáo mal remediada que tinha na sua força de trabalho o ganha-pão. Assim, com pão se ganhava o pão.

Figura 2 - Pratos regionais e distribuição da produção cerealífera em Portugal (trigo, milho e centeio).

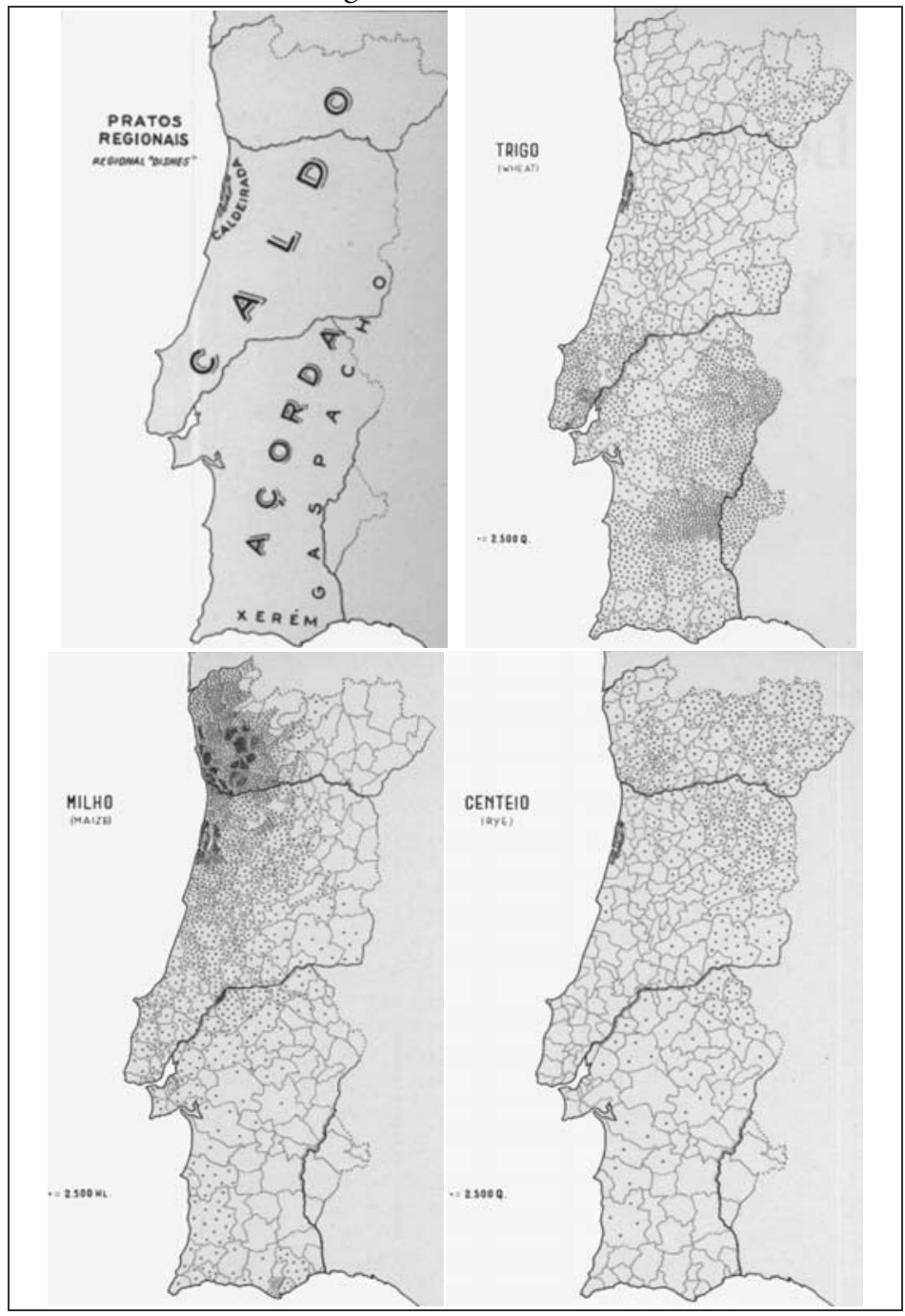

Fonte: Girão, 1958. 
Hoje, como é do conhecimento geral, multiplicam-se os formatos de pão e as suas características. As padas, as bicas, e os papos-secos, o pão de calo e o molete (próximo do pão espanhol), o bijú e a pinha (com influências gaulesas), a viana (de origem austríaca).

Perante esta internacionalização persistem ainda, por todas as regióes e em certas padarias, um saber/fazer, uma linguagem e um conjunto de gestos específicos herdados do passado, que constituem a Cultura do Páo. Esta culturaserve de linha orientadora para todos os projectos de patrimonializaçáo deste produto que é simultaneamente para além de símbolo social, religioso, económico, também territorial.

Os pães tradicionais, quer de trigo, quer de centeio, quer de milho, fazem parte do nosso património culinário. São produtos culturais e familiares que sobrevivem enquanto dáo resposta a uma necessidade, a uma expectativa, a um plano alimentar, gastronómico e identitário.

Assim, as Terras de Pão que têm associadas confrarias, feiras, festas, rotas, associaçôes e parques molinológicos em lugares que têm no pão o seu ex-líbris, como sucede, entre outras, em Terena (Reguengos de Monsaraz), em Caçarelhos (Vimioso), em Tomar, em Favaios, em Ul (Oliveira de Azeméis), fazem parte de um património a valorizar.

\section{O MUNDO TRADICIONAL E O PROCESSO DE MODERNIZAÇÃO.}

Numa sociedade aberta e num contexto de diversificação da oferta alimentar, os terroirs oferecem não apenas um potencial de diferenças, mas constituem também um dispositivo de integração na economia mundial. Os produtos de terroir e a cozinha local são então pontos de integração do global no local, tanto económica como simbolicamente (Ascher, 2009).

A globalização inscreve as práticas, os hábitos e os comportamentos alimentares na tensão entre a homogeneização, formalizada na americanização ou Mcdonaldização, e a diversificação que a micro-diversificação, o regionalismo das tradiçóes alimentares locais afirmam. Daqui resulta uma mestiçagem do acto alimentar, que colocam as normas gastronómicas entre a "terra reencontrada" e o exótico da cozinha mundial (Policarpo, 2008). Ainda assim, a globalização ganha importância e usa o fast-food como referência gastronómica das sociedades contemporâneas, das desenvolvidas às em vias de desenvolvimento.

É de sublinhar que esta tendência hegemónica está relacionada com o reaproveitamento do pão: o cachorro quente, os burritos, os bocadillhos, o hambúrguer, as baguetes, as pizzas são precisamente reconquistas ajustadas do pão na mesa contemporânea, cuja presença a nível mundial passa pelo preço cómodo e pelo marketing que lhe estão associados. Assim, não nos devemos surpreender muito com a expansão do ecletismo alimentar no mundo. A fusionfood e o fooding estão na moda em todas as metrópoles A humanidade é muito reactiva às novas ideias, o que assegura hoje uma difusão rápida e mundial de certos alimentos e certas necessidades, do hambúrguer à pizza, por exemplo. Mas ela também cria diversidade permanente.

A maioria das receitas culinárias da França contemporânea não é mais antiga do que o séc. XIX, o que também é verdade para os costumes folclóricos, para muitas das arquitecturas rurais e urbanas. Importa pois olhar de forma distanciada as tradiçôes eternas no domínio alimentar. Os produtos de origem não devem ser tomados por vacas sagradas mas por geradores de emoções, produtos em contínua transformação. 
As maneiras de comer são diversas. Os Americanos mostram ter um apetite feroz, insistem em comer o mais depressa possível, em especial os businessmen de Chicago ou de Nova Iorque. Nestas duas cidades existem, desde o início do século XX, self-services onde servem refeiçóes aos colarinhos brancos que as pedem ao balcáo e as consomem à mesa, tudo a um ritmo rápido. Pode-se trabalhar e comer ao mesmo tempo; comer e, aparentemente, desenvolver qualquer outra actividade (Flandrin \& Montanari, 1996). Foi esta forma de fazer que nos leva hoje ao fast-food, mas que nos deixa a possibilidade de aceder, também, ao tempo de qualidade (Urry, 1995) esteios de resistência ao pragmatismo anglo-saxónico que olha a alimentação sobretudo como um modo de reproduçáo da força de trabalho.

Ganhar formas rejuvenescidas de restauração e de produtos que ou caíram em desuso ou têm a sua produção muito localizada e necessitam de viagens e visitas, com o propósito de os encontrar e provar, é uma ocupação que tem expressão nos tempos de lazer, no desenvolvimento e formação das pessoas através da procura de nichos de oferta turística onde se incluem a gastronomia e o pão.

Actualmente, a cozinha da aldeia e o carácter sazonal dos alimentos tornaram-se valores enobrecidos, objectivos primordiais e prestigiosos. $\mathrm{O}$ enaltecimento da diferença e a preservação da identidade cultural não pertencem a uma temática saudosista e retrógrada. Pertencem antes ao presente e ao futuro, uma vez que se reportam a uma conquista recente ainda em vias de consolidação. (Flandrin \& Montanari, 1996)

\section{A REDESCOBERTA DOS LUGARES E DOS SEUS PRODUTOS NO SISTEMA TURÍSTICO.}

São diversas as festas de cariz religioso que hoje têm no pão a sua principal referência. É o caso da Festa dos Tabuleiros ou Festa do Divino Espírito Santo, ex-líbris turístico de terras de Alto Tejo, muitas delas com origem nas festas de colheitas ${ }^{1}$.

Figura 3 - Museu do Pão e do Vinho de Favaios. Uma transformação através do pão.
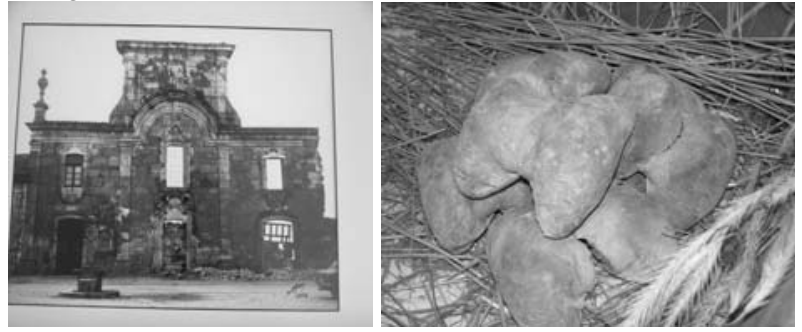

Fonte: Autores

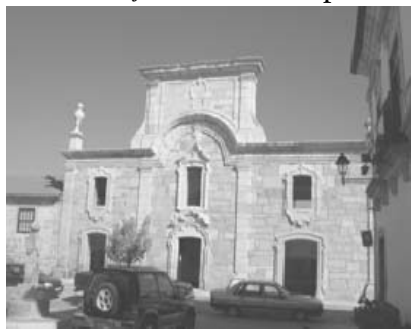

Também as Festas da Ascensão (dia da Espiga) são festas de alusivas ao pão em muitas terras portuguesas, em associação directa com a Páscoa. De igual modo, o pão aparece

\footnotetext{
${ }^{1} \mathrm{O}$ Tabuleiro deve ter a altura da rapariga que o leva à cabeça, com trinta pães enfiados em cinco ou seis canas rematadas por uma coroa encimada pela Pomba do Espírito Santo ou pela Cruz de Cristo.
} 
associado ao $1^{\circ}$ de Novembro, quando as crianças saem à rua e em pequenos grupos pedem, de porta em porta, o páo-por-deus ${ }^{2}$.

Outras formas de relação do pão surge relacionado com a religiosidade, vivendo portas meias, assumindo um significado espiritual associado à importância material, como sucede no Santuário da Senhora da Lapa, em Sernancelhe, onde as padarias e o rio com os seus moinhos, onde se moía o trigo, deram origem ao Pão alvo da Lapa ou Trigo da Lapa.

Por sua vez, as Confrarias e Associaçóes têm um papel fundamental na divulgação e valorização do páo da terra, dando expressáo à patrimonializaçáo do produto ao lugar e promovendo o desenvolvimento local através de eventos diversos, como sucede com a Confraria do Pão Alentejano, com a Associação de Produtores de Pão de Ul, com a Confraria da Broa de Avintes, entre outras.

Aparecem, também, museus dedicados ao pão, contando a história e criando estórias, servindo de âncoras e marcas territoriais em terras de pão. O Museu do Pão do Sabugueiro e o Museu do Páo e do Vinho de Favaios (Sabrosa) (Figura 3) são disso exemplo, com este último a mostrar, uma faceta de inegável valor, de uma requalificação patrimonial.

A este processo de marketing territorial associam-se as rotas turísticas do pão, com uma vertente participativa com grande importância, dando expressão a um produto de qualidade e a um saber-fazer muito característico que funcionam como montra de lugares. A Rota da Broa, que oferece um percurso pedestre nas aldeias de Candal e Póvoa das Leiras (Sáo Pedro do Sul); a Rota das Padeiras, em Vale de Ílhavo; com o Ciclo do Linho e o Ciclo do Páo de Vale de Cambra; com as Tradiçóes de Tendais, em Cinfães: das Vessadas ao Cozer do Páo, são exemplos deste processo.

Aparecem outras rotas que envolvendo o pão apresentam valências turísticas diferentes. É o caso dos fornos comunitários existentes nas Aldeias de Xisto (por exemplo, Figueira e Martim Branco) atractivo turístico central de uma Rota com créditos firmados. Os fornos de pão assumem uma importância simbólica relevante para lugares e populaçóes. Disso é exemplo o forno medieval de Avelar, ligado às Festas de Nossa Senhora da Guia e ao cumprimento de promessas ${ }^{3}$.

Os limites do texto não nos dão a possibilidade de alargar muito o âmbito dos exemplos e diversidade da temática do pão em associação com a valorização do turismo. Estas referências servem apenas como indicador das potencialidades deste produto e dos lugares com ele associados. Além de ser um instrumento para o conhecimento dos lugares, pode converter-se num modo de assunção de um turismo participativo, de expressão de lazeres potenciadores de desenvolvimento local, de valorização de actores locais, nomeadamente os responsáveis pela informação, divulgação e conhecimento de produtos e lugares.

\section{NOTA FINAL}

As terras de pão, dos recursos, aos instrumentos, aos produtos e ao saber-fazer podem converter-se num elemento de patrimonialização de inegável importância. $\mathrm{O}$ pão deixou

\footnotetext{
${ }^{2}$ Em algumas terras conhecido por Bolinhos e bolinhós.

${ }^{3}$ Com esta finalidade a pessoa entrava no Forno bem quente, levando nas mãos a farinha para cozer e fazer um pão enorme, e na boca, para sua protecção, flores como instrumento de protecção divina. O pão era, depois de cozido, distribuído gratuitamente pelos peregrinos.
} 
de ter a centralidade que tinha há algumas dezenas de anos enquanto bem de necessidade básica, mas passou a ter significado em níveis superiores de necessidades. Assim é, porque o acesso ao pão se democratizou mas, contudo, a procura do pão tradição/lugar/saber-fazer local tornou-se, como a inovação, num novo produto a conseguir pelos grupos sociais dominantes. Perante a importância das novas formas de lazer e turismo na identidade destas classes dominantes, a descoberta de novos lugares, novos modos e novos tempos, através do pão enquanto saber-fazer e produto tradicional, identifica-se com a sua procura da diferença e do específico, na tentativa de contrapor ao lazer e turismo massificados um modo de consumo distinto.

\section{REFERÊNCIAS BIBLIOGRÁFICAS}

A Terra, o Homem e o Pão 2002, I Congresso Português de Cultura Mediterrânica, Confraria do Páo, Presidência da República Portuguesa, Terrena.

Ascher, F. 2005, Le Mangeur Hypermoderne. Éditions Odile Jacob, Paris,

Barboff, M. at al. 2008, O Pão em Portugal. Ediçóes Inapa, Lisboa

Bell, D \& Valentine, G. 1997, Consuming geographies. We are where we eat. Routledge, New York.

Brunet, R. et al. 1993, Les mots de la Géographie, dictionnaire critique. 3 Montpellier, Reclus, Paris.

Cartier, C \& e Lew, A. 2005, Seductions of place. Routledege, Oxon.

Claval, P. 1995, La géographie culturelle. Nathan Université, Paris.

Connerton, P. 1993, Como as sociedades recordam, Celta Editora, Oeiras.

Cresswell, T. 2004, Place. A short introduction. Blackwell, Londres.

DiMéo, Guy (1998). Géographie sociale et territoires. Nathan, Paris.,

Dollfus, O. 2001, La mondialisation. Presses de Sciences, Paris.

Dulau, R. \& Pitte, J.-R. 1999, Géographie des odeurs. Géographie et cultures. L'Harmattan, Paris.

Valeri, R. 1989, A alimentação. Enciclopédia Einaudi, Vol. 16, INCM, Lisboa.

Entrikin, J. N. 1991, The betweenness of place. Polity Press, Cambridge.

Fernandez, A. 2009, El Pan. In La historia en la mesa - Especial Clio, Junho, Mc Editions, Barcelona, pp. 74-75.

Flandrin, J.-L. e Montanari, M. 1996, História da Alimentação. Vol. 1 e 2, Terramar, Lisboa.

Fonseca, C. 1986, 'Do pão de Deus ao pão que o Diabo amassou', in Revista de Historia das Ideias, 8, O Sagrado e o Profano, IHTI, Faculdade de Letras, Coimbra, pp. 263-279.

Gama, A. 1992, 'Urbanização difusa e territorialidade local', in Revista Crítica de Ciências Sociais, 34, Vol. III, Coimbra.

Girão, A. 1958, Atlas de Portugal, Instituto de Estudos Geográficos, Coimbra.

Harvey, D. (1998), The condition of postmodernity, Blackwell, Oxford.

Lefèbvre, H.1974, La production de l'espace. Gallimard, Paris.

Levy, J. et al., 2003, Dictionnaire de géographie et de l'espace des sociétés, Bélin, Paris.

Lopes, P. 2006, A modernidade alimentar. CEOS-Inquéritos 2, Ediçóes Colibri, Lisboa

Massey, D. 1994, Space, place and gender. Polity Press, Cambridge.

Montanari, M \& Pitte, J.-R. 2009 Les frontières alimentaires. CNRS, Paris.

Ritzer, G. 1993, The Mcdonaldization of society. Pine Forge Press, Sage, Newbury Park.

Santos, N. P. \& Gama, A. 2008, Lazer. Da libertação do tempo à conquista das práticas. Imprensa da Universidade de Coimbra, Coimbra.

Santos, N.P. (2001) - A sociedade de consumo e os espaços vividos pelas famílias Centro de Estudos Geográficos, Edições Colibri, Lisboa.

Tuan, Y. F. 1970, 'Space and Place: Humanistic perspective', in Human Geography, Ed. J. Agnew, D. Livingstone \& A. Rogers, Blackwell, Oxford.

Urry, J. 1995, Consuming places. Routledge, Londres.

Vasconcelos, J. L. 1975, Etnografia Portuguesa, Vol VI, INCM, Lisboa. 